\title{
Contribuições de Daniil Elkonin para o ensino da educação física na infância
}

\section{Daniil Elkonin's contributions to the teaching of physical education in childhood}

\section{Contribuciones de Daniil Elkonin para la enseñanza de la educación física en la infancia}

\author{
(iD) Edna Santos de Carvalho \\ Universidade Estadual de Feira de Santana, Feira de Santana, Bahia, Brasil. \\ E-mail: ednacarvalhoef@gmail.com \\ iD Tiago Nicola Lavoura \\ Universidade Estadual de Santa Cruz, Ilhéus, Bahia, Brasil. \\ E-mail: nicolalavoura@gmail.com
}

\begin{abstract}
Resumo: O estudo analisou as contribuições teóricas de Daniil B. Elkonin e da psicologia histórico-cultural para o trabalho pedagógico da Educação Física (EF) na educação infantil, a fim de problematizar as possibilidades de realização desta disciplina curricular com vistas ao assim chamado ensino desenvolvente. Atentou-se, especialmente, à relação entre ensino e desenvolvimento e suas possibilidades por meio do jogo protagonizado. Para tanto, a pesquisa, teórico-conceitual de caráter bibliográfico, utilizou procedimentos analíticos a partir de fontes de diversos autores que já se debruçaram sobre o tema. Concluiu-se que a EF pode contribuir para o desenvolvimento infantil ao possibilitar a apropriação dos conhecimentos da cultura corporal por meio da atividade-guia do jogo protagonizado.
\end{abstract}

Palavras-chave: Educação Física. Desenvolvimento infantil. Atividade. Jogo protagonizado. 
Abstract: The study analyzed the theoretical contributions of Daniil B. Elkonin and historical cultural psychology for the pedagogical work of Physical Education (PE) in early childhood education with the objective of discuss the possibilities of achievement of this curricular discipline aiming at denominated developmental teaching. Particular attention was paid to the relationship between teaching and development and its possibilities through the protagonist game. Therefore, the conceptual theoretical research of bibliographic character used analytical procedures from sources of several authors who have already dedicated themselves on the subject. It was concluded that PE can contribute to child development by enabling the appropriation of body culture knowledge through the guiding activity of the protagonist game.

Keywords: Physical Education. Child development. Activity. Protagonist game.

Resumen: El estudio analizó las contribuciones teóricas de Daniil B. Elkonin y la psicología histórico cultural al trabajo pedagógico de la Educación Física (EF) en la educación de la primera infancia, con el fin de discutir las posibilidades de realización de esta asignatura curricular con miras a la llamada enseñanza del desarrollo. Se prestó especial atención a la relación entre la enseñanza y el desarrollo y sus posibilidades a través del juego protagonista. Por lo tanto, la investigación teóricoconceptual de carácter bibliográfico utilizó procedimientos analíticos de fuentes de varios autores que ya han abordado el tema. Se concluyó que la EF puede contribuir al desarrollo del niño al permitir la apropiación del conocimiento de la cultura corporal a través de la actividad guía del juego protagonista.

Palabras clave: Educación Física. Desarrollo infantil. Actividad. Juego protagonista.

Submetido em: 14-08-2019

Aceito em: 01-06-2020 
Contribuições de Daniil Elkonin para o ensino da educação física na infância

\section{Introdução}

A infância se configura como uma fase de extrema relevância para a formação do indivíduo, pois é nela que se estabelece a base estrutural para as demais etapas do desenvolvimento. Nesse sentido, a educação infantil, etapa inicial da educação básica, é essencial para o desenvolvimento do psiquismo e suas funções específicas, que possibilitarão a criança compreender e internalizar o mundo humano (MARTINS, 2007).

O psicólogo russo Daniil Borisovich Elkonin apresenta um importante legado acerca da compreensão dos períodos do desenvolvimento infantil, evidenciando a necessidade de se levar em consideração as atividades e as relações presentes na dinâmica da formação da personalidade da criança, situando-se como um autor de referência no âmbito da psicologia histórico-cultural (ELKONIN, 1969a, 1969b, 1987a, 1987b, 1998). Dentre seus trabaIhos, destaca-se o que traz um importante estudo sobre o papel do jogo protagonizado no desenvolvimento infantil. Suas análises oferecem aos educadores orientações para a prática pedagógica intencional e voltada a uma significativa contribuição na formação dos alunos.

Apoiado nos preceitos da assim chamada escola de Vigotski, Elkonin parte do pressuposto de que o desenvolvimento do psiquismo está condicionado à formação de comportamentos complexos culturalmente instituídos. Como afirma Vygotsky (1996), a formação humana demanda a apropriação de tudo que já foi construído pelos indivíduos ao longo da sua história. Assim, enquanto componente curricular da educação escolar, a EF tem uma importante função no processo educativo dos indivíduos, podendo dar ricas contribuições para o desenvolvimento infantil por meio da transmissão de conteúdos da cultura corporal (TEIXEIRA, 2018).

Consideramos, assim, a cultura corporal, o objeto de ensino da EF, como um acervo de significações histórico-sociais produzidas culturalmente pela humanidade a partir das atividades do 
Contribuições de Daniil Elkonin para o ensino da educação física na infância Edna Santos de Carvalho • Tiago Nicola Lavoura

jogo, do esporte, da dança, das lutas, da ginástica e da capoeira. Ao inserir-se no campo escolar, essa disciplina tem como função a transmissão-assimilação dos conhecimentos que oportunizem a vivência e a experimentação, bem como a análise teórica crítica, radical e de conjunto destas formas sociais de atividades humanas constitutivas da prática social. Essa condição é fundamental para o alcance de uma reflexão pedagógica ampliada que proporcione aos alunos a capacidade de constatação, interpretação, compreensão e explicação da realidade social (COLETIVO DE AUTORES, 2012).

Tendo em vista esses elementos, este estudo teve como objetivo analisar de que maneira a EF pode contribuir para o desenvolvimento infantil a partir do trabalho pedagógico fundamentado nos preceitos da teoria do jogo protagonizado, desenvolvida por Elkonin, com base nos fundamentos da psicologia histórico-cultural. Para tanto, a pesquisa teórico-conceitual de caráter bibliográfico utilizou-se das contribuições de diversos autores que já se debruçaram sobre o tema, cujos resultados sintetizamos neste artigo em duas partes. Primeiro, apresentamos algumas categorias teóricas desenvolvidas por Elkonin, configuradas como fundamentos da psicologia histórico-cultural, notadamente acerca das questões afetas ao desenvolvimento humano e sua relação com o processo educativo. Posteriormente, atentamo-nos à exposição das principais características da atividade-guia do jogo protagonizado e suas possibilidades de ensino da EF na educação infantil.

\section{Daniil B. Elkonin: um desconhecido no campo da Edu- cação Física brasileira}

O psicólogo russo Daniil Borisovich Elkonin (1904-1984) traz uma importante contribuição à compreensão da dinâmica e das características do desenvolvimento humano e sua relação com o processo educativo da criança. Como aponta Lazaretti (2011), apesar de ser conhecido no Brasil por seu livro Psicologia do Jogo, esse autor é responsável por um imenso legado advindo de trabalhos 
Contribuições de Daniil Elkonin para o ensino da educação física na infância Edna Santos de Carvalho • Tiago Nicola Lavoura

sobre o processo de aquisição do conhecimento na educação escolar, o desenvolvimento do pensamento e da linguagem, reflexões sobre o processo de aprendizagem da escrita e da leitura, bem como métodos de ensino a partir da consideração dos períodos de desenvolvimento humano. Nascido no período pré-revolucionário do desenrolar da revolução russa de 1917, Elkonin acompanhou as profundas transformações ocorridas no interior da sociedade soviética, desenvolvendo seus estudos em meio a um contexto orientado por princípios socialistas (LAZARETI, 2011).

Inspirado por Vigotski e sua escola, Elkonin desenvolveu seus estudos tendo como referencial teórico o marxismo, em busca de uma nova concepção de ser humano e de sociedade, cuja base epistemológica marxista fosse a orientadora e a formadora de uma nova psicologia e uma nova educação escolar (LAZARETTI, 2011). Formada pelo trabalho coletivo de importantes psicólogos soviéticos, a escola de Vigotski foi caracterizada pela intenção de atingir um objetivo comum: compreender o ser humano e o desenvolvimento do seu psiquismo à luz do materialismo histórico-dialético. São, portanto, tais fundamentos da psicologia histórico-cultural que forneceram embasamento às investigações de Elkonin sobre a formação e o desenvolvimento da criança desde o nascimento até o final da idade escolar.

Segundo ele, os processos psíquicos culturalmente instituídos na criança têm início na infância, transformando-se e aperfeiçoando-se ao longo de toda a vida do indivíduo. Assim, a formação da criança não se dá por meio daquilo que já existe no nascimento, mas é um autêntico processo de desenvolvimento psíquico, norteado pelas condições sociais e pela educação (LAZARETTI, 2011). Elkonin (1969a, 1969b, 1987b) desenvolveu importantes análises, intermediando psicologia e pedagogia, na busca de solução para os problemas práticos da educação escolar com vistas ao chamado ensino desenvolvente. Ou seja, o ensino enquanto promotor de desenvolvimento, sempre considerando o desenvolvimento humano como um processo profundamente marcado pelas relações sociais estabelecidas pelos sujeitos entre si e com a própria 
Contribuições de Daniil Elkonin para o ensino da educação física na infância Edna Santos de Carvalho • Tiago Nicola Lavoura

realidade. Ressaltando que o desenvolvimento psíquico está diretamente relacionado à apropriação da experiência social, Elkonin $(1987 a, 1998)$ dedicou-se à investigação do papel do jogo protagonizado no desenvolvimento infantil.

Compreender o psiquismo humano a partir dos fundamentos da psicologia histórico-cultural implica, necessariamente, em atentar para o processo de internalização da cultura e suas inferências ao longo do desenvolvimento do indivíduo. Vygotsky (1996), ao conceber o ser humano enquanto ser social, traz à tona a improbabilidade de ele se desenvolver somente com seus aparatos biológicos. Além disso, é necessário compreender que os indivíduos não só produzem cultura, mas, também, são produtos dela, revelando assim a preponderância dos aspectos culturais sobre os naturais, cujo desenvolvimento está subordinado às atividades que eles desenvolvem junto à natureza e em sociedade. Na esteira dos fundamentos do campo do marxismo, é a atividade de trabaIho a que se configura como primeva e ontologicamente fundante do ser social (LEONTIEV, 2004).

Os estudos de Leontiev (2004), no interior da escola de Vigotski, foram enriquecedores para a compreensão e desenvolvimento da categoria da atividade, esta que explicita a relação social desenvolvida pelos seres humanos, tanto no aspecto filogênico quanto ontogênico. Sendo assim, considera-se que cada geração humana, que se objetiva socialmente, carrega como precedência o universo de objetivações sociais criadas por gerações anteriores. A apropriação de tudo o que há de humano pelas novas gerações não se dá de outra maneira senão pela participação no trabalho, na produção da vida material e nas diversas formas de atividades sociais, as mais diversas, que vão sendo desenvolvidas no interior dos processos de vida social, tais como a educação, a arte, a política, a religião, a filosofia e a cultura de maneira geral.

É a partir deste entendimento que se configuram as relações entre desenvolvimento do psiquismo e humanização dos indivíduos. Tal perspectiva historicizadora revela a primazia dos aspectos sociais sobre os aspectos naturais e biológicos no processo 
Contribuições de Daniil Elkonin para o ensino da educação física na infância Edna Santos de Carvalho • Tiago Nicola Lavoura

de desenvolvimento humano. Nestes termos, a qualidade deste desenvolvimento também é produto construído histórico-socialmente e está diretamente relacionada às condições de vida social, nas quais o patrimônio histórico-cultural é disponibilizado aos indivíduos singulares (ELKONIN, 1998; LEONTIEV, 2004; VYGOTSKY, 1998).

Martins (2013) observa a estreita e recíproca relação entre atividade e desenvolvimento, ressaltando que a criança vai reorganizando qualitativamente seus comportamentos, culturalmente instituídos, na medida em que os mesmos se tornam uma exigência, tanto em termos funcionais quanto estruturais, nas atividades que ela realiza ao longo de sua vida. Portanto, as formas de ser e estar no mundo não são naturalmente constituídas.

Ao mesmo tempo, não é qualquer atividade que implica em desenvolvimento, mas sim aquela que, concomitantemente, exige uma nova estrutura orgânica e resulta em uma nova função psíquica. Além disso, o simples contato da criança com as objetivações sociais não possibilita a apropriação dos signos humanos que tais objetivações carregam. É necessário um processo ativo em que haja mediação entre o sujeito e o objeto, delineando-se também uma finalidade, uma intenção. Essa mediação, segundo Martins (2007), não significa ligação ou vinculação entre partes, mas, sim, aquilo que se interpõe na relação sujeito-objeto, transformando ou exigindo transformação do próprio sujeito.

De acordo com Vygotsky (2010), as atividades mediadas propulsoras de mudanças no funcionamento psíquico são permeadas por um processo de internalização de signos. Tais atividades, condensadas com os signos da cultura, levam a alterações no psiquismo humano, uma vez que a mediação dos signos promove a ruptura dos atos imediatos para atos orientados pela consciência, transformando as funções psíquicas elementares em funções psíquicas superiores (VYGOTSKY, 1996).

Conforme evidenciou o precursor desta escola psicológica soviética, as funções psíquicas elementares são garantidas pelo 
Contribuições de Daniil Elkonin para o ensino da educação física na infância Edna Santos de Carvalho • Tiago Nicola Lavoura

aparato biológico da espécie, e são também comuns tanto a seres humanos quanto aos animais. Já as funções psíquicas superiores resultam das atividades mediadas que colocam a conduta humana em um patamar superior de desenvolvimento e de complexidade em relação aos demais animais, ou seja, são funções eminentemente culturais (VYGOTSKY, 1996).

Elkonin (1987b) aponta que, para entender as forças condutoras do psiquismo da criança, é necessário compreender que as atividades ocorrem de distintas formas e com base em diferentes conteúdos, revelando a possibilidade de sistematização de uma periodização do desenvolvimento humano. Segundo ele, o desenvolvimento psíquico é determinado pelo conjunto das atividades dominantes ou atividades-guia, as quais, ao se modificarem, culminam na mudança dos próprios estágios ou períodos de desenvolvimento.

A atividade-guia desempenha a principal forma de relação do sujeito com o mundo à sua volta, e é dela que surgem as principais mudanças na formação da personalidade do indivíduo, além de propiciar o surgimento das outras atividades ao longo do desenvolvimento (LEONTIEV, 1978). Não se trata da atividade que a criança executa na maior parte do tempo, mas, sim, daquela que produz novas formas de comportamento, promovendo o seu desenvolvimento cultural.

Para Elkonin (1998) e Leontiev (1978), por meio de necessidades específicas exigidas pela atividade-guia, desenvolve-se uma ou mais funções psíquicas. Esta atividade que guia e conduz o desenvolvimento é que caracteriza cada estágio ou período do mesmo, proporcionando novas funções psíquicas, pois, à medida que vão surgindo novas necessidades, exigem-se a superação das antigas funções. O processo de superação de uma função psíquica por outra e das mudanças de atividades-guia é marcado por crises, indicando que a atividade desempenhada pelo sujeito em determinado período de vida não corresponde mais às suas atuais necessidades, colocando-se a exigência da realização de novas atividades. 
Contribuições de Daniil Elkonin para o ensino da educação física na infância Edna Santos de Carvalho • Tiago Nicola Lavoura

Elkonin (1987b, 1998) chegou à seguinte classificação das atividades-guia: atividade de comunicação emocional direta, atividade objetal-manipulatória, atividade de jogo protagonizado (também denominada de jogos de papéis sociais), atividade de estudo, atividade de comunicação íntima pessoal e atividade profissional/ estudo, respectivamente. Observou, assim, que os processos psíquicos dependem dos motivos e das tarefas da atividade na qual estão incluídos, esclarecendo que, no processo de desenvolvimento, cada nova atividade é gestada dentro da sua antecessora, nascendo dialeticamente do ventre da atividade anterior. Logo, a atividade que conduz o desenvolvimento em um período promove o desenvolvimento de uma nova atividade, que por sua vez guiará o desenvolvimento no período posterior.

Passemos agora à análise do jogo protagonizado, buscando compreender sua natureza e estrutura, bem como reconhecer sua importância na educação escolar enquanto atividade mediadora do desenvolvimento das crianças na educação infantil para, posteriormente, relacioná-lo com o ensino da EF.

\section{O jogo protagonizado e o ensino da Educação Física na educação infantil}

A primeira tese esclarecida por Elkonin (1998) é a de que o jogo protagonizado tem origem histórica e nasce como resultado da mudança do lugar da criança em meio às relações sociais. Como não pode ser inserida na sociedade por meio de uma atividade direta, a criança reconstitui, por meio do jogo, ações que ainda não lhe estão acessíveis. Assim, o uso de objetos, as relações e as regras estabelecidas da atividade humana, os papéis sociais e suas representações objetivas são aprendidos e reproduzidos pelas crianças de forma coletiva no jogo protagonizado.

Para substituir objetos reais e reconstituir a ação dos adultos, entram em cena os objetos lúdicos, trazendo uma forma específica de ação com eles, caracterizando-se como uma ação lúdica. $\mathrm{A}$ 
Contribuições de Daniil Elkonin para o ensino da educação física na infância Edna Santos de Carvalho • Tiago Nicola Lavoura

utilização de objetos substitutos significa para Elkonin (1998) que o papel social é a unidade fundamental do jogo. Por meio da necessidade de agir como o adulto, a criança cria uma situação imaginária, interpretando papéis sociais, desempenhando as ações que o caracterizam. Para isso, não hesita em substituir objetos originais por funcionais, exigidos pela ação que deseja realizar. O papel é o aspecto característico central do jogo, constituindo-se como possibilidade de inserção da criança nas atividades humanas e nas relações estabelecidas nessas atividades (ELKONIN, 1998).

Elkonin (1998) explica que pela ação lúdica observa-se um tipo especial de ação, na qual seu significado se transmite de forma sintética e abreviada. Pensemos no exemplo de crianças brincando de hospital. Para a criança que interpreta o médico examinando o paciente, basta que essa faça um gesto sintetizador da ação real do médico ouvindo o som do coração. Quando vai receitar o remédio, pode utilizar uma caneta e um papel imaginários, executando ações que transmitam a ideia de escrever sobre um papel. $\mathrm{O}$ importante para ela é transmitir às outras crianças que interpretam os pacientes o significado da ação. Para Elkonin (1998), quanto mais abreviadas e sintéticas são as ações lúdicas, mais profunda é a representação das relações sociais reproduzidas.

Compreender tal afirmação exige recorrer aos aspectos das ações lúdicas na brincadeira. Para que haja a síntese e a abreviação na ação da criança é preciso que antes ela transponha os significados, utilizando objetos substitutos. A substituição de um objeto por outro é a base para a possibilidade de executar, com o objeto lúdico, a ação representante do papel. Graças a essa substituição, o aspecto técnico operacional da ação fica subordinado à plasticidade que transmite somente seu significado geral (examinar o paciente, passar a lição, levar para passear, dar comida). A abreviação e a síntese das ações lúdicas sinalizam que a criança está assimilando as significações sociais objetivas das ações existentes na atividade humana (ELKONIN, 1998).

Conforme esse autor, a contradição fundamental da natureza das ações com o objeto é que, de um lado, as ações com o objeto 
Contribuições de Daniil Elkonin para o ensino da educação física na infância Edna Santos de Carvalho • Tiago Nicola Lavoura

contêm a significação social do objeto e, de outro, apresentam as propriedades operacionais referentes às suas características físicas. A ação com um pedaço de papel como se fosse um prato ajuda a separar a ação do objeto da real situação habitual. A tomada de consciência da ação como tal é favorecida por essa operação. Nos dizeres de Elkonin (1998) é difícil para a criança observar seu próprio comportamento, mas no jogo ela observa e separa o "eu real" do "eu imaginário" e assim controla suas ações de maneira relativamente mais fácil. A adoção de um papel exige da criança novas formas de agir com os objetos, o que favorece as funções psíquicas, culminando em formas mais desenvolvidas de pensamento, linguagem, atenção, percepção, memória, imaginação e sentimentos, formando a consciência (MARTINS; FACCI, 2016).

Conforme Lazaretti (2016), na brincadeira de papéis sociais as crianças orientam suas ações para atingir um fim, e isso é base para a formação da consciência. No entanto, o conteúdo da brincadeira depende das suas relações concretas de vida, pois representa as relações vividas, percebidas e sentidas pela criança (VYGOTSKY, 2008). Daí a importância da intervenção do professor para que haja aprendizado acerca das ações com o objeto. $O$ ato educativo na fase pré-escolar deve voltar-se para o ensino das ações significadas com base na relação sujeito-adulto social e sujeito-objeto social, de modo a possibilitar às crianças a capacidade de representação de papéis. Essa intervenção, no entanto, implica em conhecer minuciosamente qual o papel do professor de educação infantil, bem como do jogo protagonizado como uma importante ferramenta em suas ações pedagógicas com esse público.

Martins e Facci (2016) afirmam que as formas de comportamentos culturais que surgem e/ou se desenvolvem no jogo protagonizado se referem ao comportamento voluntário que sintetiza diferentes funções psíquicas, tais como: atenção voluntária, memória lógica, a linguagem significada e o controle deliberado das próprias ações. Fruto da internalização de signos, o comportamento voluntário surge, primeiramente, nas relações sociais objetivamente existentes no âmbito da coletividade humana e delas 
Contribuições de Daniil Elkonin para o ensino da educação física na infância Edna Santos de Carvalho • Tiago Nicola Lavoura

o indivíduo singular toma parte. Concretizando-se a chamada lei genética geral do desenvolvimento, postulada por Vygotski (1995, p. 150), cuja premissa é a de que "[...] toda função entra em cena duas vezes, em dois planos, primeiro no plano social e depois no psicológico, ao princípio entre os homens como categoria interpsíquica e logo no interior da criança como categoria intrapsíquica".

No jogo de papéis sociais é possível encontrar a explicação de como se dá a condição social dessa atividade para a criança. Tratase dos signos representados pelo papel, um instrumento externo que possibilita à criança o domínio dos estímulos que incidem sobre ela, e assim, a criança domina sua própria conduta. Ao interpretar um determinado papel social, a criança se esforça para se comportar conforme a figura representada, subordinando-se às regras e normas de conduta, o que acaba por determinar um aspecto central no seu desenvolvimento, porque a conduz a um desenvolvimento iminente. Este é definido por Vygotsky (1998) como um tipo de desenvolvimento atingido pelo sujeito à medida que produz formas de comportamento social alcançadas com a ajuda direta ou por imitação de um adulto, portanto, de forma interpsíquica, uma vez que, individualmente, não seria possível a ocorrência destas neoformações.

Esse processo é o principal gerador de desenvolvimento psíquico, pois produz as mais importantes mudanças, preparando o indivíduo para um novo e superior nível de desenvolvimento (ELKONIN, 1998). Em que pese o fato de que, em suas atividades cotidianas, as crianças elaboram representações de papéis, o jogo protagonizado, trabalhado pedagogicamente com crianças na idade pré-escolar, torna-se uma importante e fundamental atividade potencializadora de desenvolvimento infantil. Fato que nos provoca a pensar nas possibilidades de realização de processos educativos no âmbito da EF e do ensino de seu objeto e conteúdos escolares.

De nossa parte, concebemos que o professor de EF tem a tarefa de ampliar o universo cultural dos escolares por meio da transmissão de um rico acervo de significações histórico-sociais, 
Contribuições de Daniil Elkonin para o ensino da educação física na infância Edna Santos de Carvalho • Tiago Nicola Lavoura

cuja apropriação permitirá aos alunos, ao longo do processo de escolarização, compreender e explicar o que são e como se desenvolveram as diversas atividades constitutivas deste objeto de ensino denominado de cultura corporal - jogo, esporte, dança, lutas e ginástica. Os conteúdos específicos desta disciplina no currículo podem proporcionar contribuições para o desenvolvimento dos alunos (NASCIMENTO; DANTAS, 2009), desde que sejam consideradas as atividades-guia adequadas que impulsionem tal desenvolvimento. O jogo protagonizado, no interior do processo educativo, exige uma organização intencional e a construção de uma forma específica do processo pedagógico. Em cada atividade elaborada pelo professor é preciso definir o que dessa realidade deve ser apropriado pela criança. No caso da EF, é preciso que a criança perceba e se relacione com os significados de cada atividade da cultura corporal que esteja sendo trabalhada pedagogicamente.

Por meio do jogo protagonizado é possível direcionar a criança para a identificação e constatação de determinadas significações sociais, das quais o objeto e os conteúdos de ensino da EF são portadores, possibilitando a ela a apropriação daquilo que ainda não possui constituído internamente. É papel do professor desenvolver uma intervenção de modo a propiciar as condições para a internalização destes significados pela criança. Para tanto, é necessário o trato pedagógico com os conteúdos da cultura corporal de forma lúdica, utilizando os recursos necessários para esta apreensão.

Alguns estudos vêm demonstrando possibilidades de desenvolvimento do ensino de conteúdos escolares na educação infantil, tomando o jogo protagonizado como atividade-guia (MAGALHÃES, 2016; NASCIMENTO; DANTAS, 2009; PASQUALINI, 2018; TEIXEIRA, 2018).

Ao organizar sua atividade docente, o professor de EF deve respeitar a forma principal pela qual a criança se apropria da realidade, objetivando provocar novas experiências e estabelecer novas inter-relações psíquicas (PICCOLO, 2010). Pasqualini (2018) e Pasqualini e Brigatto (2018) apresentam contribuições importan- 
Contribuições de Daniil Elkonin para o ensino da educação física na infância Edna Santos de Carvalho • Tiago Nicola Lavoura

tes analisando possibilidades de intervenção pedagógica direta e indireta com o jogo protagonizado, considerando-se a organização sistemática do ensino que visa à ampliação do universo simbólico do pré-escolar. As intervenções pedagógicas indiretas são consideradas por Elkonin (1987a) aquelas circunscritas às condições prévias para a emergência da situação imaginária e do enredo do jogo protagonizado, criando assim as condições iniciais necessárias para o desenvolvimento do mesmo. Já as intervenções pedagógicas diretas são aquelas realizadas pelo adulto (professor) no próprio desenrolar do jogo, durante a representação de papéis operada pelas crianças.

No que se refere ao ensino de conteúdos escolares da EF e o jogo protagonizado na pré-escola, apresentamos a seguir algumas possibilidades didáticas que sintetizam elementos de intervenções pedagógicas indiretas e diretas, exemplificadas neste texto, considerando o trato com o ensino de conteúdos da capoeira, mas que podem ser generalizadas pensando-se em outros conteúdos de ensino de outras formas de atividades da cultura corporal, visando a ampliar o conhecimento e o repertório simbólico das crianças acerca desse objeto de conhecimento, bem como auxiliar o desenvolvimento e a evolução do 'enredo' do próprio jogo durante a ação de representação de papéis:

- intervenções pedagógicas indiretas realizadas com i) atividades de desenho e pintura, recortagem e colagem ou modelagem que permitam às crianças identificarem e reconhecerem atores sociais da capoeira (negros escravos, quilombolas, senhores do engenho, capitães do mato), apresentação de instrumentos e objetos sociais (berimbau, atabaques, caxixi, agogô), ações lúdicas de ensino de fundamentos de ataque e defesa (benção, esquiva, martelo, meia lua, au, dentre outros); ii) ações com exibição de vídeos de animação tematizando aspectos gerais e específicos da capoeira, assim como elementos históricos, distinções, diferenças e semelhanças entre capoeira regional e angola, alguns fundamentos básicos, utilização de instrumentos e suas funções sociais; iii) ações com ex- 
Contribuições de Daniil Elkonin para o ensino da educação física na infância Edna Santos de Carvalho • Tiago Nicola Lavoura

posição de músicas e rodas cantadas que permitam o reconhecimento da musicalidade da capoeira e seus instrumentos; iv) ações lúdicas envolvendo o uso social dos objetos e instrumentos da capoeira, como jogo da memória, jogos de adivinhação, e outros; v) visitação e apresentação de um grupo de capoeira da cidade com vistas à participação e interação coletiva; vi) preparação de um roteiro de perguntas e curiosidades direcionadas a um mestre de capoeira ou praticante acerca do universo da capoeira.

- intervenções pedagógicas diretas realizadas para que a ação do jogo protagonizado ocorra, e as crianças possam desenvolver modelos de ações nas quais os papéis sociais sejam representados com base em conhecimentos históricos, culturais, dentro da dinâmica e da estrutura de uma roda de capoeira, das canções e da sua musicalidade, das movimentações básicas do agir e do executar o jogo. O papel do professor é fundamental para o enriquecimento do enredo e do alcance dos níveis mais complexos de execução do jogo protagonizado pelas crianças. Todavia, é preciso tomar os devidos cuidados para que sua intervenção não ocasione a interrupção do jogo.

Importante destacar que as intervenções pedagógicas indiretas são consideradas acessórias ao desenvolvimento do jogo protagonizado, visto cumprirem a função de criar as condições de ampliação e enriquecimento deste último. Por seu turno, as intervenções pedagógicas diretas adquirem a função de linha principal de desenvolvimento do jogo protagonizado em si mesmo. Ambas são essenciais para o alcance do efeito desenvolvente do jogo protagonizado.

Por fim, há que se destacar que, para Vygotsky (2005), o ensino deve incidir sobre aquilo que ainda não foi construído na criança, mas que está em vias de ser. Por isso a importância da organização do ensino, levando em consideração o nível de desenvolvimento da criança, bem como a principal forma pela qual ela 
Contribuições de Daniil Elkonin para o ensino da educação física na infância Edna Santos de Carvalho • Tiago Nicola Lavoura

se relaciona e apreende a cultura à sua volta nesta etapa do seu desenvolvimento.

\section{Considerações finais}

O interesse central deste trabalho esteve voltado para a compreensão do jogo protagonizado no sentido de problematizar as contribuições da EF para o desenvolvimento infantil, tendo-se o trabalho pedagógico realizado sob os fundamentos da teoria de Elkonin, em particular seus estudos sobre a Psicologia do Jogo, considerando também o estofo teórico da psicologia histórico-cultural. Tal anseio investigativo possibilitou a compreensão da necessidade de o ensino sistematizado da cultura corporal fazer parte do trabalho pedagógico na educação infantil.

Do delineamento da pesquisa, o artigo estruturou-se em duas seções. A primeira trouxe uma breve apresentação sobre Elkonin e sua relação com a psicologia histórico-cultural, além dos fundamentos de tal teoria psicológica acerca do desenvolvimento humano. Assim, refletiu-se sobre a concepção de psiquismo, a relação entre o biológico e cultural, a aquisição das funções psíquicas superiores e a análise da atividade-guia enquanto propulsora do desenvolvimento infantil, enfatizando a relação com o processo educativo. Elkonin (1987b) evidencia a compreensão da periodização do desenvolvimento como necessária à elaboração de estratégias pedagógicas, pois é preciso conhecer as atividades que desempenham a principal forma de relação da criança com mundo.

Na segunda seção do texto, a discussão referente ao jogo protagonizado instaurou-se como elemento fundamental para pensar a EF e suas ações pedagógicas para com os indivíduos em nível pré-escolar, entendendo a sistematização de conteúdos como fundamental à apropriação, pelos alunos, dos significados contidos nessas práticas. Pelas obras de Elkonin (1987a, 1998), Vygotsky (1996, 1998 2008) e Leontiev (2004) foi possível perceber as possibilidades de contribuição da EF, considerando-se o jogo protagoni- 
Contribuições de Daniil Elkonin para o ensino da educação física na infância Edna Santos de Carvalho • Tiago Nicola Lavoura

zado como uma importante ferramenta pedagógica, vislumbrando uma educação que de fato desempenhe sua função social.

Embora não devam ser encaradas como pragmáticas e utilitaristas, as possibilidades de intervenção pedagógica apresentadas no texto fomentam novas formas de pensar e agir com a EF no ensino infantil, realçando as contribuições dessa disciplina nesta etapa de escolarização. Nessa perspectiva, a socialização do rico universo de significações histórico-sociais que constituem a cultura corporal na forma de conteúdos de ensino às crianças, por meio do jogo protagonizado, pode se caracterizar como importante instrumento de trabalho educativo com vistas ao desenvolvimento dos indivíduos.

\section{Referências}

\section{COLETIVO DE AUTORES. Metodologia do ensino de Educação}

Física. 2. ed. São Paulo: Cortez, 2012.

ELKONIN, D. B. Desarrollo psiquico del nino desde el nacimiento hasta el ingreso en la escuela. In. SMIRNOV, A. A. et al. Psicología. Mexico: Grijalbo, 1969a, p. 504-522.

ELKONIN, D. B. Desarrollo psiquico de los escolares. In: SMIRNOV, A. A. et al. Psicologia. Mexico: Grijalbo, 1969b, p. 523-560.

ELKONIN, D. B. Problemas psicológicos del juego en la edad preescolar. In V. Davídov \& M. Shuare (Orgs.), La psicologia evolutiva e pedagogica en la URSS. Moscú: Editorial Progreso, 1987a, p. 83-102.

ELKONIN, D. B. Sobre el problema de la periodizacion del desarrollo psíquico em la infância. In: SHUARE, M. (org.) La psicologia evolutiva y pedagogica en la URSS. Moscú: Editorial Progreso, 1987b, p. 104-124.

ELKONIN, D. B. Psicologia do jogo. São Paulo: Martins Fontes, 1998. 
Contribuições de Daniil Elkonin para o ensino da educação física na infância

LAZARETTI, L. M. D. B. Elkonin: vida e obra de um autor da Psicologia histórico-cultural/Lucinéia Maria Lazaretti. São Paulo: Editora Unesp, 2011.

LAZARETTI, L. M. Idade pré-escolar (3-6 anos) e a educação infantil: a brincadeira de papéis sociais e o ensino sistematizado. In: MARTINS, L. M.; ABRANTES, A. A.; FACCI, M. G. D. (Orgs.). Periodização histórico-cultural do desenvolvimento psíquico: do nascimento à velhice. 1. ed. Campinas, SP: Autores Associados, p. 129-148. 2016.

LEONTIEV, A. N. O desenvolvimento do psiquismo. Lisboa: Livros Horizonte, 1978.

LEONTIEV, A. N. O homem e a cultura. In: O desenvolvimento do psiquismo. 2. ed. São Paulo: Centauro, 2004.

MARTINS. L. M. Algumas reflexões sobre o desenvolvimento omnilateral dos educandos. In: MEIRA, M. E. M.; FACCI, M. G. D. (Orgs.) Psicologia histórico-cultural: contribuição para o encontra entre a subjetividade e a educação. São Paulo: Casa do Psicólogo, 2007.

MARTINS. L. M. $\mathbf{O}$ desenvolvimento do psiquismo e a educação escolar: contribuições à luz da psicologia histórico-cultural e da pedagogia histórico-crítica. Campinas, SP: Autores Associados, 2013.

MARTINS. L. M. Psicologia histórico-cultural, pedagogia histórico-crítica e desenvolvimento humano In: MARTINS, M. L; ABRANTES, A. A; FACCI, D. J. M. In: MARTINS, L. M.; ABRANTES, A. A.; FACCI, M. G. D. (Orgs.). Periodização histórico-cultural do desenvolvimento psíquico: do nascimento à velhice. Campinas, SP: Autores Associados, 2016, p. 13-33.

MARTINS, C. J; FACCI, D. J. M. A transição da educação infantil para o ensino fundamental: dos jogos de papéis à atividade de estudo. In: MARTINS, M. L; ABRANTES, A. A; FACCI, D. J. M. (Orgs).

Periodização do desenvolvimento histórico-cultural do desenvolvimento psíquico: do nascimento à velhice. Campinas, SP: Autores Associados, 2016, p. 149-167. 
Contribuições de Daniil Elkonin para o ensino da educação física na infância

MAGALHÃES, G. M. Análise da atividade-guia da criança na

Primeira Infância: contribuições da Psicologia Histórico-Cultural para a avaliação do desenvolvimento infantil dentro de instituições de ensino. 2016. 162 f. Tese (Doutorado em Educação Escolar) - Faculdade de Ciências e Letras, Universidade Estadual Paulista, Araraquara, São Paulo, 2016.

NASCIMENTO, C. P; DANTAS, L. E. P. B. T. O desenvolvimento histórico-cultural da criança nas aulas de educação física: possibilidades de trabalho a partir da atividade principal e dos temas. Revista Brasileira de Ciências e Esporte, Campinas, SP, setembro, 2009. v. 31, n. 1, p. 147-161.

PASQUALINI. J. C. Seis teses histórico-críticas sobre o currículo escolar e o problema da especificidade da educação infantil. 2018. 52 f. Relatório (Pós-Doutorado em educação) - Faculdade de Educação, Universidade Estadual de Campinas, São Paulo, Campinas, 2018.

PASQUALINI, J. C.; BRIGATTO, F. O. Brincadeira protagonizada como atividade-guia do desenvolvimento da criança pré-escolar: possibilidades didáticas. Anais: XIX ENDIPE - Encontro Nacional de Didática e Prática de Ensino, set. 2018, Salvador-BA.

PICCOLO, G, M. O jogo por uma perspectiva histórico-cultural.

Revista Brasileira de Ciências e Esporte, Campinas, SP, janeiro, 2010. v. 31, n. 2, p. 187-202.

TEIXEIRA, R. D. Educação Física na pré-escola: contribuições da abordagem crítico-superadora. 2018. 157 f. Tese (Doutorado em Educação) - Faculdade de Educação, Universidade Federal da Bahia, Salvador, 2018.

VYGOTSKI, L. S. Historia del desarrollo de las funciones psíquicas superiores. Obras Escogidas. Tomo III. Madri: Visor/MEC, 1995. VYGOTSKY, L. S. A formação social da mente: o desenvolvimento dos processos psicológicos superiores. 5. ed. São Paulo: Martins Fontes, 1996. (Série Psicologia e Pedagogia). 
Contribuições de Daniil Elkonin para o ensino da educação física na infância Edna Santos de Carvalho • Tiago Nicola Lavoura

VYGOTSKY, L. S. Pensamento e linguagem. Tradução Jeferson Luiz Camargo. 2. ed. São Paulo: Martins Fontes, 1998. (Série Psicologia e Pedagogia).

VYGOTSKY, L. S. A brincadeira e seu papel no desenvolvimento psíquico da criança. (Zóia Prestes, Tradução). Revista Virtual de Gestão de Iniciativas Sociais, 8, 23-36. Rio de Janeiro, 2008. (Original Work Published in 1933).

VYGOTSKY, L. S. Aprendizagem e desenvolvimento intelectual na idade escolar. In: VYGOTSKY, L. S.; LURIA, A. R.; LEONTIEV, A. N. Linguagem, desenvolvimento e aprendizagem. 11. ed. São Paulo: Ícone, 2010, p. 103-117.

\section{Publisher}

Universidade Federal de Goiás. Faculdade de Educação Física e Dança. Publicação no Portal de Periódicos UFG. As ideias expressadas neste artigo são de responsabilidade de seus autores, não representando, necessariamente, a opinião dos editores ou da universidade. 